\title{
RAÇA E RACISMO: os Desafios dos Direitos Humanos na Sociedade Moderna
}

\begin{abstract}
Vanessa Vilela Berbel
Doutoranda pela Pontifícia Universidade Católica de São Paulo (PUC/SP) na área de Filosofia e Teoria Geral do Direito (Bolsista-Capes), com estágio doutoral perante o lus Gentium Conimbrigae/Centro de Direitos Humanos (IGC) da Universidade de Coimbra; mestre em Direito pela Universidade de São Paulo (Fadusp/USP) na mesma área de concentração (2012); pós-graduada em Direito e Processo Tributário pelo Ibet/SP e graduada em Direito pela Universidade Estadual de Londrina (2006).vberbel@ yahoo.com.br
\end{abstract}

Resumo:

0 conceito de raça, etimologicamente, origina-se do termo latim ratio e denota a categorização de espécies. Ocorre que a distinção inicialmente realizada em bases científicas estritas extrapolou o campo do saber e passou a ser tratada como projeto social para a evolução da espécie. Os efeitos deletérios causados por esta distorção marcam diversas sociedades, entre elas a brasileira. Entender como o conceito de raça migrou das bases científicas para a estrutura social e como este ato impacta a sociedade moderna é o escopo do presente artigo.

\section{Palavras-chave:}

Raça. Racismo. Sociedade. Direito

\section{RACE AND RACISM:}

The challenges of human rights In modern society

\section{Abstract:}

The concept of race, etymologically, comes from the Latin term ratio and denotes the categorization of species. It turns out that the distinction initially held in strict scientific basis overstepped the field of knowledge and began to be treated as a social project for the evolution 
of species. The deleterious effects caused by this distortion mark several societies, among them Brazilian. Understanding how the concept of race moved the scientific basis for social structure and how this act impact modern society is the scope of this article.

\section{Keywords:}

Race. Racism. Society. Law

Recebido em: 19/8/2016

Aceito em: 14/10/2017

\section{Sumário:}

1 Introdução. 2 A distinção como parte da observação. 3 A construção da ideia de raça e do racismo. $4 \mathrm{~A}$ raça em números. $5 \mathrm{~A}$ superação da discriminação por meio de um compromisso de consciências de múltiplas cores. 6 Conclusões. 7 Referências. 


\section{INTRODUÇÃO}

Todo dia 20 de novembro é dia de comemorar a "Consciência Negra" brasileira, mas temos o que comemorar? Conseguimos redescobrir ou descobrir a negritude de nossa memória histórica? Nessa data, em 1695, foi morto Zumbi, um dos últimos líderes do Quilombo dos Palmares, que se transformou em um grande ícone da resistência negra ao escravismo e da luta pela liberdade. E por que dia 20 de novembro e não 13 de maio, dia da abolição da escravatura? Porque Zumbi dos Palmares remonta a uma luta pela visibilidade do problema. E isso não é pouca coisa, pois a questão racial sempre foi negada no Brasil, sob a ficção de uma "democracia racial".

Sem intenção alguma de menosprezar a imensa contribuição dos imigrantes europeus para o desenvolvimento brasileiro, certo é que, no século 19, enquanto os negros vivenciavam a perspectiva de uma falsa liberdade por uma série de leis editadas para satisfazer às exigências da Inglaterra por uma abolição no país chamadas também, por Marcelo Neves de "leis álibis" (2008, p. 254), conhecidas no vocabulário popular de "leis para inglês ver" - como a Lei do Ventre Livre e a Lei dos Sexagenários -, a eugenização social era fomentada pelo Estado por meio de um incentivo às imigraçôes do europeu polaco fornecendo-lhes terra e capital; forma-se, assim, a estrutura social paradoxal brasileira. O ápice: "Treze de maio, traição, liberdade sem asas e fome sem pão", assim definia o poeta Oliveira Silveira a data que demarcou o fim da escravatura.

Antes, porém, de adentrar no tema, gostaria de fazer dois parênteses: quem escreve é alguém que não vive, não experimenta as diversas formas de racismo que a sociedade mundial pratica; portanto, trato do problema a partir da perspectiva do humano que almeja uma sociedade mais justa, com consciência de que faz parte do problema; falo na perspectiva daqueles que acreditam num projeto de nação que contemple a diversidade engendrada no nosso processo histórico e traz consigo algumas dúvidas: $\mathrm{O}$ conceito de raça é de fato necessário? Existe raça entre os seres humanos, seja em termos biológicos ou sociais? Como posso desvendar as raízes do racismo e do eugenismo no Brasil e sua permanência devastadora? 
Vive-se em uma sociedade de paradoxos. Paradoxos que apresentam desafios constantes para a efetivação dos direitos humanos, para o estabelecimento da igualdade entre os seres e o convívio harmônico e equilibrado. Ao mesmo tempo que se avança no reconhecimento de direitos, nasce, em contraposição, uma forte tendência para a sua supressão, sob o argumento de conservação da família, dos bons valores e da ordem.

Entre luzes e trevas, atrasos e retrocessos, reconhecimento de direitos e sonegação de direitos, entre igualdade entre os seres e reconhecimento de diferenças, construímos nossos paradoxos e desafios. É preciso romper essa dialética e encontrar uma síntese que supere a paleta de cores da pele (branco, preto, vermelho, amarelo, marrom, etc.) para considerar tão somente o humano demasiado humano.

Para que possamos pensar sobre essa perspectiva de superação precisamos saber como se deu o "mito da raça".

\section{A DISTINÇÃO COMO PARTE DA OBSERVAÇÃO}

Distinguir é prática habitual dos seres humanos; é a partir do distinguir, do diferenciar, do conhecer diferenças que se elabora conhecimento. A observação pressupóe distinção, afastamento do observador daquilo que é observado; em um primeiro momento, "aquele que observa algo deve diferenciar-se do observado; ou seja, deve ter uma relaçáo consigo mesmo para poder se diferenciar". Apenas Deus, como se vê na teologia de Nicolau de Cusa, não necessita se distinguir para observar (LUHMANN, 2009, p. 86). É, portanto, onipresente e onisciente; no mais, a distinção faz parte da observação.

Também é possível, no entanto, a partir do estabelecimento de diferenças, não apenas conhecer os elementos de distinção, mas usá-los com o objetivo ideológico de segregar, a partir da atribuiçấo inadequada de valores às categorias. Cria-se um paradoxo: ao mesmo tem que distinguir permite ver o problema pode resultar na reprodução de novas desigualdades. Como alertam Feriani e Oliveira (2013, p. 352): 
Apesar de marcadores sociais (p. ex.: geração, classe, raça, gênero, sexualidade) assumirem significados diversos em diferentes contextos e situaçóes, muitas vezes, por meio das políticas identitárias, corre-se o risco de serem congelados sob um viés biológico, tornando-se uma armadilha para os próprios grupos que reivindicam tais marcas como forma de obter a igualdade e a universalidade do Direito.

Como, então, o ato de distinguir, diferenciar e catalogar o ser humano deixa de ser uma atividade científica e passa a servir de base para a estruturaçáo social?

\section{A CONSTRUÇÃO DA IDEIA DE RAÇA E DO RACISMO}

Nas sociedades humanas a prática da discriminação (no uso deletério do termo) é tão disseminada quanto nefasta; pode-se afirmar que, historicamente, onde existe a diferença, existem indivíduos cujas vidas são prejudicadas por pertencerem a um ou outro grupo que foge a determinadas categorias. A discriminação não é um fenômeno brasileiro; como todos sabem, existe em todos os continentes, países e culturas.

Entender que seu grupo é mais relevante, mais potente, mais capaz de estabelecer um modo de vida melhor do que os demais é uma característica inerente à história humana, à qual não podemos atribuir um fato histórico específico para sua criação. Há uma repulsa natural ao estranhamento que o outro lhe causa e a tentativa de reduzi-lo a espécimes inferiores, com o objetivo de fazer seu modo de vida prevalecer. Foi assim, por exemplo, que os gregos denominavam os estrangeiros de bárbaros (MAROZI, 2010, p. 311-315) e os inuítes do ártico foram considerados primitivos e batizados pelos europeus de esquimós ou "comedores de carne crua". Como cantou Caetano: "É que narciso acha feio o que não é espelho". Podemos dizer então, o ser humano é narcisista!

Essa discriminação etnocentrista conduziu às maiores guerras da humanidade, como a Guerra da Armênia, a Segunda Guerra Mundial (1939-1945), o genocídio cambojano (1975-1979), o genocídio em Ruanda (1994), entre tantos outros. 
A pergunta é: Como se passou de um etnocentrismo para a ficção da existência de raças? E quando, ainda, a ideia de raça deixou de ser uma categoria científica para virar doutrina, um tipo de conhecimento que se mantém por repetição e, em casos de distorção, por ignorância e preconceito?

O racismo é um dos produtos mais indignos e perversos da relação saber e poder. Guarda vinculação direta com a afirmação das ciências positivas, pois se ancora na perspectiva de raça inicialmente criada com base científica.

A ideia de raça é coisa muito recente. Tem em média dois séculos e se cria a partir do racialismo, antiga doutrina protocientífica que afirmava que as diferenças biológicas existentes no interior da espécie humana eram grandes o bastante para diferenciar raças com qualidades psicológicas, intelectuais ou de caráter distinto. A partir desta perspectiva importada da Botânica e da Zoologia é que se origina o conceito de raça, cuja etimologia tem suas bases no termo latino ratio, que significa sorte, categoria, espécie (MUNANGA, 2016).

Carl Von Linné (Lineu), sociólogo, botânico e médico sueco do século 18 (1707 a 1778), pai da taxonomia moderna, ramo da ciência voltado para a ordenação de seres vivos, foi o primeiro a falar em quatro raças humanas: europeia, africana, asiática e americana. Após, Blumenbach (1752-1840), médico alemão, no final do século 18 em seu livro On the Natural Variety of Mankind forma a distinçáo de raças a partir de cores, criando assim a aquarela racial: Caucasianos - raça branca; Mongóis - raça amarela; Malaios - raça marrom; Etíopes - raça negra, e Americanos, raça vermelha. ${ }^{1}$

A categorização de raças sai da Biologia e passa a ser um elemento para a descrição da história humana com Arthur de Gobineau, escritor e filósofo francês do final do século 19 (1816 - 1882). Este filósofo relacionou a diferenciação de raça ao desenvolvimento das naçóes e escreveu o "Ensaio sobre a desigualdade das raças humanas" com a ideia central de estabelecer um escalonamento de raças (GOMES, 2011).

${ }^{1}$ Disponível em: <http://www.understandingrace.org/history/science/early_class.html>. 
Gobineau achava que a miscigenação de raças humanas causava a degeneração do ser e, por isso, considerou uma penitência o período de sua estadia no Brasil, em que teve de conviver com os degenerados mestiços brasileiros; esse tormento era apenas atenuado pela convivência com seu amigo D. Pedro II, considerado por ele como um legítimo ariano (GOMES, 2011). Apesar da inexistência de bases científicas claras de seu pensamento, as ideias do conde Gobineau foram recepcionadas pela comunidade da época, o que demonstra como perspectivas absolutamente descartáveis podem ser produzidas por pessoas loucas e, mesmo assim, serem apropriadas pela sociedade em razão de um argumento de autoridade. Hannah Arendt, em seu livro $A$ origem do totalitarismo, descreve Gobineau como uma mistura de nobre frustrado e intelectual romântico, que pode ser considerado um dos precursores do racismo (ARENDT, 2011).

A relação entre raça humana e desenvolvimento social encontra sua face mais perversa no projeto de eugenização do nazismo, cujas raízes remontam às ideias de Chamberlain, em seu livro As fundaçóes do século XIX, que vai inspirar os principais ideólogos do regime. Neste livro ele conta a história do progresso humano como história racial, protagonizado pela raça ariana, mas isso é assunto para uma outra história.

O fato é que esta ideia de raça foi absorvida na sociedade brasileira. Não serviu para iniciar a escravidáo e a comercializaçáo de negros como mercadorias, pois estas não precisaram de nenhuma justificativa racial, uma vez que se iniciaram muito antes da ideia de raça e se fundavam numa perspectiva econômica. Esta perspectiva, porém, amparou a manutenção da escravidão mesmo após o início do Iluminismo e justificou a perpetuação de uma estrutura desigual na sociedade brasileira.

Logo após o abolicionismo, em 1888, inicia-se um processo de eugenização da sociedade brasileira, encampado por uma ideia de que o negro, como classe inferior que era, produzia o retrocesso social e, portanto, era necessário "branquear a sociedade brasileira”, por meio de um projeto de imigração. Segundo as ideias de Gobineau, amigo pessoal de D. Pedro II, a raça brasileira, oriunda da miscigenação, era fadada ao insucesso e seria superada, em aproximadamente 200 anos, pelas raças superiores. Era necessário, portanto, proceder ao processo de melhoria racial. 
Gobineau realizou missóes diplomáticas no país em 1869 e nunca escondeu suas ideias de que o país não teria futuro, pois estava repleto de raças inferiores. É urgente o início de um projeto de "restauração" da sociedade brasileira por meio do incentivo às imigraçóes dos europeus, afirma. Segundo ele:

Mas, se em lugar de se reproduzir por ela mesma, a população brasileira estivesse em situação de minorar com vantagem os elementos desgraçados de sua constituição étnica atual, fortificando-os por alianças de valor mais alto com raças europeias, então o movimento de destruição observado em suas classes cessaria e daria lugar a um curso totalmente oposto. A raça se levantaria, a saúde pública melhoraria, o temperamento moral se veria recuperado e as modificaçóes mais felizes se introduziriam no estado social de este admirável país (GOBINEAU apud GOMES, 2011).

O mestiço, pardo, mulato, era visto, então, como uma classe intermediária que inevitavelmente seria extinta no decorrer do tempo, quando triunfariam os elementos do homem branco, geneticamente superior. Esse projeto foi incentivado por meio de políticas migratórias e deu ensejo à formação da consciência coletiva do negro como um subumano ou um "humano degenerado". Quando alguns mulatos teimaram em apresentar habilidades extraordinárias, eram catalogados como mulatos mais similares aos brancos e, se isso ocorria com os negros, eram chamados de "negros de alma branca".

A ideologia da eugenia expandiu-se no mais tardio reduto escravocrata do mundo durante os séculos 19 e 20. Como já afirmado, a diferença de raças não foi um motivo para se iniciar a escravidão, mas serviu para embasar a sua manutençáo mesmo diante de todas as evidências iluministas de que não havia diferença entre os seres. Caiu como uma luva para a sociedade patrimonialista e escravocrata brasileira. "Para quem defendia o direito do proprietário sobre uma propriedade humana, essa lógica chegou com a intenção de legitimar a escravidáo ou, diante do seu fim, fortalecer a ideia de que a liberdade náo seria acompanhada de igualdade" (AGUILAR FILHO, 2015).

A lei teve papel importante no processo de incentivo à eugenização da sociedade brasileira. Na Constituição brasileira de 1934, em seu artigo 138, está escrito que: 
Art. 138 - Incumbe à União, aos Estados e aos Municípios, nos termos das leis respectivas:

a) assegurar amparo aos desvalidos, criando serviços especializados e animando os serviços sociais, cuja orientação procurarão coordenar;

b) estimular a educação eugênica (BRASIL, 1934).

Eugenia, termo criado por Francis Galton (1822-1911), primo de Darwin, nada mais é do que o controle social que pode melhorar as qualidades raciais das futuras geraçóes. Sua teoria visava a fornecer "as bases teóricas para não só compreender os mecanismos da transmissão dos caracteres entre as geraçóes, como também contribuir positivamente para a melhora das características do conjunto populacional” (DEL CONT, 2008, p. 201).

No Brasil das décadas de 30 e 40 do século 20, a eugenia foi distorcida; extraída do projeto científico transformou-se em projeto social, sendo a "educação eugênica" aplicada às crianças, em especial aos filhos da classe trabalhadora mais empobrecida, sobretudo, nos termos da época, entre "órfãos e abandonados, pretos ou pardos, débeis ou atrasados". Lourenço Filho (1897-1970), educador, pedagogo e apoiador do governo de Getúlio Vargas, chegou a defender que crianças pretas possuíam um déficit natural de aprendizagem em relação às brancas, sendo necessário se criar classes seletivas. Um olhar sobre o Brasil de Vargas (1930-1945) revela a discriminação racial como política estatal, em que a segregação e a desigualdade de direitos entre cidadãos foram legalizadas, teorizadas e praticadas no país.

Com a falência do projeto de eugenização e a demonstração de toda a sua monstruosidade em decorrência dos horrores da Segunda Guerra Mundial, o racismo à brasileira foi transformado no mito da "democracia racial". Em uma comparaçáo com o projeto de eugenia dos Estados Unidos da América buscou-se falaciosamente demonstrar que aqui nada disso ocorrera, afinal náo esterilizamos pessoas (como as 7.000 mulheres esterilizadas no Estado da Virginia).

\section{A RAÇA EM NÚMEROS}

As relaçóes sociais no Brasil foram pautadas pela existência de relaçóes raciais. Se o argumento de que raças não existe, então por que, até o momento, não conseguimos mudar a estrutura social que aparece em números? Se não existem negros e brancos, 
por ser a sociedade brasileira altamente miscigenada, então por que os números nos contrariam e mostram que, aqueles que se autodeclaram negros, possuem maior chance de virem a ser encarcerados ou mortos?

Tratar o indivíduo de forma genérica, geral e abstrata não parece ajudar a modificar os problemas estruturais causados por séculos de crença no mito de raças superiores e inferiores. Como demonstrado em tópico anterior, a ideia de raça não se limitou à classificação científica de grupos humanos a partir de suas características distintivas; foi além, hierarquizou, construiu uma escala social de valores e, mais:

(...) O fizeram erigindo uma relação intrínseca entre o biológico (cor da pele, traços morfológicos) e as qualidades psicológicas, morais, intelectuais e culturais. Assim, os indivíduos da raça "branca", foram decretados coletivamente superiores aos da raça "negra” e "amarela”, em função de suas características físicas hereditárias, tais como a cor clara da pele, o formato do crânio (dolicocefalia), a forma dos lábios, do nariz, do queixo, etc., que segundo pensavam, os tornam mais bonitos, mais inteligentes, mais honestos, mais inventivos, etc., e consequentemente mais aptos para dirigir e dominar as outras raças, principalmente a negra, mais escura de todas e consequentemente considerada como a mais estúpida, mais emocional, menos honesta, menos inteligente e portanto a mais sujeita à escravidão e a todas as formas de dominaçâo (MUNANGA, 2016).

A justiça exige, simultaneamente, redistribuição e reconhecimento de identidade e, conforme assevera Flávia Piovesan, "ao lado do direito à igualdade, surge, também, como direito fundamental, o direito à diferença. Importa o respeito à diferença e à diversidade, o que lhes assegura um tratamento especial" (PIOVESAN, 2014, p. 71).

Os negros são, em números, as maiores vítimas da violência e os que sofrem mais com a pobreza. Eles também têm pouca representatividade nas esferas políticas e têm renda média muito menor que a dos ditos brancos.

Dados do IBGE² de 2014 mostram que:

2 Síntese de Indicadores Sociais: uma análise das condiçôes de vida da população brasileira 2014. IBGE - Instituto Brasileiro de Geografia e Estatística. Disponível em: <http://biblioteca.ibge.gov. br/visualizacao/livros/liv91983.pdf>. Acesso em: 19 nov. 2015. 
a) A população negra é a que mais sofre com a informalidade no emprego: 48,7\% da população negra estão realizando trabalhos informais em todo o país, em contraposição a $34,7 \%$ da população branca;

b) No quesito distribuição de rendimentos per capita, considerando o universo de pessoas que vivem de rendimento do trabalho (excluindo-se, portanto, programas governamentais de transferência de renda e outras fontes de rendimento), temos que: (i) considerando o percentual dos 10\% mais pobres dos entrevistados, $75 \%$ são pretos ou pardos. Em 2004 eram 72,8\% de pretos ou pardos e 26,9\% de brancos nesse grupo - não se sabe se aumentou os que se declaram negros ou se esse percentual reflete, de fato, um empobrecimento da população negra, mas, em qualquer das hipóteses, é bastante preocupante; e (ii) considerando o percentual dos 1\% mais ricos dos entrevistados, apenas $14,6 \%$ são pretos e pardos.

c) A frequência líquida ao Ensino Fundamental na faixa etária de 6 a 14 anos é similar para negros e brancos $(92,7 \%$ para brancos e $92,4 \%$ para negros e pardos). Já nos anos mais avançados da escolarização, temos uma taxa de frequência escolar líquida em pontos percentuais muito maior para os jovens brancos do que jovens pretos ou pardos. As estatísticas de 2013 (IBGE) apontam: no Ensino Médio (entre 15 e 17 anos) temos a taxa de 63,6\% de brancos contra 49,5\% de negros. Por sua vez, no Ensino Superior (18 a 24 anos) temos a taxa de 23,5\% de acesso para os brancos, em contraposição a 10,8\% dos negros.

d) A existência de curso superior completo entre pessoas de 25 a 34 anos de idade é distribuída no percentual de $23,3 \%$ para brancos contra $8,4 \%$ para pretos e pardos.

e) E, ainda, mesmo aqueles que cursaram o Ensino Superior, temos que a adequação da idade em relação ao curso frequentado ainda é bastante desigual dependendo da cor ou raça do estudante. Enquanto do total de estudantes brancos de 18 a 24 anos 69,4\% frequentavam o Ensino Superior, apenas 40,7\% dos jovens estudantes pretos ou pardos cursavam o mesmo nível.

Os dados do Ipea mostram ainda que, no universo entre negros e brancos, quem mais sofre são as mulheres negras, as quais carregam o peso de uma dupla discriminação: a do sexo e da raça. Aplicado ao ambiente de trabalho, por exemplo, temos que, segundo texto para discussão elaborado por Sergei Soares (2000, p. 7): 
Em primeiro lugar, algumas categorias de pessoas marcadas por certas características com as quais nasceram - o sexo e a cor da pele - percebem salários horários menores ou muito menores do que os salários horários percebidos por homens brancos. Em segundo lugar, esse hiato tem-se encurtado para duas dessas categorias e permanecido inalterado para a outra.

No caso, a categoria em que se observou náo haver perspectiva de mudança efetiva é o salário pago a mulheres negras. Em publicação mais recente, o Dossiê Mulheres Negras, publicado pelo Ipea, cobre a situação da mulher negra durante os anos de 1995 a 2009 e, novamente, demonstra que o racismo e o sexismo combinam-se para delinear na sociedade visóes que estereotipam e classificam capacidades a partir de categorias de raça (brancos e negros) e sexo (mulheres e homens), de modo a produzir condiçóes diferenciadas de acesso a direitos e oportunidades. É preciso, portanto, pensar em formas para superação desses obstáculos, uma vez que os números não nos permitem sustentar o mito da democracia racial brasileira.

\section{A SUPERAÇÃO DA DISCRIMINAÇÃO POR MEIO DE UM COMPROMISSO DE CONSCIÊNCIAS DE MÚLTIPLAS CORES}

Açóes afirmativas são políticas públicas que buscam criar um patamar mínimo de igualdade, colocando determinadas minorias historicamente discriminadas dentro de uma possibilidade de isonomia, ou seja, visa a reduzir os efeitos atrozes da discriminaçáo racial. O desenvolvimento de um conjunto de políticas de caráter afirmativo, que se somam às importantes políticas universais, tem contribuído, sem dúvida, para a conformação de uma sociedade que avança paulatinamente rumo à igualdade.

Assim como a lei teve papel importante para a instituição do ideário racista, refletindo, nada mais nada menos, que as perspectivas sociais elitistas da época, agora demonstra exercer papel inverso, abrindo uma fenda no discurso brasileiro para desmistificar o paraíso das raças.

Algumas leis sáo emblemáticas na luta do movimento negro, entre elas a Lei 12.288/10 (Estatuto da Igualdade Racial) e a Lei no 12.711/2012 (lei que institui cotas raciais em universidades e instituiçóes de ensino técnico). 
Especificamente em relação às políticas de cotas raciais para acesso às universidades e cargos públicos, vale lembrar que o STF já decidiu, na Ação Direta de Descumprimento de Preceito Fundamental (ADPF) n. 186, de 26/4/2012, que esta espécie de ação afirmativa não contraria o princípio da igualdade, mas o estimula, ainda que atinja grupos sociais determinados, de maneira pontual, atribuindo a estes certas vantagens, por um tempo limitado, vez que busca permitir-lhes a superação de desigualdades decorrentes de situaçóes históricas particulares.

Faço um parêntese para lembrar que esse tipo de lei não é novidade e, inclusive, já foi aplicada às elites, como a Lei dos Bois, editada em 1968 pelo presidente Costa e Silva, que criava cotas para as escolas superiores de Agricultura e Veterinária e que beneficiaram diretamente os filhos de fazendeiros.

Para o Supremo Tribunal Federal "Justiça social, hoje, mais do que simplesmente redistribuir riquezas criadas pelo esforço coletivo, significa distinguir, reconhecer e incorporar à sociedade mais ampla valores culturais diversificados, muitas vezes considerados inferiores àqueles reputados dominantes" (ADPF 186).

Ocorre que a instituição desta justiça social encontra desafios. Pontuo alguns deles:

O primeiro desafio é a definição, para inserção nas açôes afirmativas, do que é ser negro. Usa-se a autodefinição de cada indivíduo - o que está a gerar bastante controvérsias, decidindo, o poder Judiciário, recentemente, pela exclusão do critério genético para o fenótipo caso assim conste no edital.

O segundo desafio é, usando-se o fenótipo e não o conceito genético: Não se estaria a produzir desigualdades de oportunidades dentro de um mesmo bojo familiar, muitas vezes? Teremos o caso de dois irmãos, filhos de negro e branco, que, possuindo aparência distinta, concorreram de forma diversa para vagas em uma mesma universidade. Não teria o filho com aparência branca elementos culturais negros e legado histórico de exclusão que justifique sua alocação na mesma categoria de seu irmão? Agora, se adotarmos o critério genético, não estaríamos retornando à perspectiva de uma "gota de sangue" que embasou o projeto eugenista norte-americano? 
O terceiro desafio é manter o discurso a respeito da existência de raças, o que poderia alimentar ainda mais a ideia da dicotomia entre homem branco e homem negro.

É por isso que a política de cotas não será capaz de mudar o ideário social sem que seja efetivada uma outra lei, que se observada for produzirá efeito mais duradouro e efetivo do que a política de cotas - sem com isso combater essa medida, a qual acredito ser eficaz dentro do seu caráter de temporalidade - que é a Lei 10.639/03.

A Lei 10.639/03 é a principal agente de transformação, mas também é a que menor efetividade tem hoje. É ela que determina o ensino da história e cultura afrobrasileira e ressalta a importância da cultura negra na formação de nossa sociedade. Ao invés de trabalhar com a ideia de raças de maneira isolada, e necessário mexer na superestrutura da sociedade brasileira, trabalhar, então, com a perspectiva de cultura e mudar o ideário deletério deixado pelas distorções históricas.

\section{CONCLUSÕES}

Demonstrou-se ao leitor que a ideia de classificar os seres humanos em raças diferentes, ao migrar das fronteiras da ciência, modificou estruturas sociais, criando a falsa perspectiva da existência de raças superiores e raças inferiores. Esta questão abriu caminhos para o racialismo e, ato contínuo, ao racismo. A superação deste mito levou alguns defensores a sugerir que fosse banida a ideia de raça; todavia o fato é que, ainda que banida fosse, a ideia de raça permanece na realidade social e política, condicionando a vida de muitos.

É preciso, portanto, mudar a superestrutura social por meio da educação; entender que o povo africano não se reduz à escravidão, ao contrário, são povos nobres, que contribuíram muitíssimo para a evolução do ser humano e que nada há de inferior em sua cultura, muito menos em sua cor. Incentivar meninos e meninas a reconhecerem algumas verdades elementares para se romper o mito da inferioridade de raças: o Egito é africano e, portanto, todo o legado desta civilização é 
negro. É preciso entender a herança africana que formou a musicalidade brasileira, a importância da africanidade para a formação da língua brasileira (como os verbos zangar, cochichar, cochilar, entre tantas outras palavras).

Necessário incentivar a população a ler as obras de Carolina Maria de Jesus (1914-1977), a mais importante escritora negra do país que foi esquecida pela História. Moradora da favela do Canindé, em São Paulo, catadora de lixo e máe de três filhos, esta escritora vendeu mais de um milhão de livros. Sua obra Quarto de Despejo foi traduzida em mais de 13 línguas e inclui o retrato da vida do pobre e negro. São da autora as frases: "A tontura da fome é pior do que a do álcool. A tontura do álcool nos impele a cantar. Mas a da fome nos faz tremer. Percebi que é horrível ter só ar dentro do estômago.» E “Eu sou negra, a fome é amarela e dói muito".

Para tanto, torna-se definitivo que nenhuma cor mais defina quem é quem, o destino de meninas e meninas ou suas competências e habilidades. Que haja um mundo de múltiplas cores e muita luz. Afinal, racismo não é como você parece, mas sim como as pessoas atribuem significação à sua aparência (tradução livre de "Racism is not about how you look, it is about how people assign meaning to how you look", de Robin D. G. Kelley, historiador).

\section{REFERÊNCIAS}

AGUILAR FILHO, Sidney. Racismo à brasileira. Disponível em: <http://www.revistadehistoria.com.br/secao/educacao/racismo-a-brasileira>. Acesso em: 20 nov. 2015.

ARENDT, Hannah. As origens do totalitarismo. São Paulo: Companhia das Letras, 2011.

BRASIL. Constituição da República dos Estados Unidos do Brasil (de 16 de julho 1934). Disponível em: <http://www.planalto.gov.br/ccivil_03/constituicao/constituicao34.htm>.

DEL CONT, Valdeir. Francis Galton: eugenia e hereditariedade. scientiæ zudia, São Paulo, v. 6, n. 2, p. 201-18, 2008. Disponível em: <http://www.scielo.br/pdf/ss/v6n2/04>.

FERIANI, Daniela; OLIVEIRA, Marcella Beraldo de. Direito, Diferença e Desigualdades. In: RODRIGUEZ, José Rodrigo; SILVA, Felipe Gonçalves. Manual de sociologia jurídica. São Paulo: Saraiva, 2013. 
GOMES, Adriana. A miscigenação do Brasil sob o olhar de Gobineau. Disponível em: <http:// www.historiaehistoria.com.br/materia.cfm?tb=professores\&id=162\#_ftn1>. Acesso em: 19 ago. 2011.

INSTITUTO BRASILEIRO DE GEOGRAFIA E ESTATÍSTICA (IBGE). Indicadores sociais: uma análise das condições de vida da população brasileira 2014. Disponível em: <http://biblioteca.ibge.gov.br/visualizacao/livros/liv91983.pdf>. Acesso em: 19 nov. 2015. INSTITUTO DE PESQUISAS ECONÔMICAS APLICADAS (Ipea). Dossiê mulheres negras: retrato das condiçóes de vida das mulheres negras no Brasil. Organizadora Mariana Mazzini Marcondes et al. Brasília: Ipea, 2013.

LUHMANN, Niklas. Introdução à teoria dos sistemas. Petrópolis, RJ: Vozes, 2009.

MAROZZI, Justin. The Way of Herodotus: Travels with the Man who Invented History. [S.1.]: Da Capo Press, 2010.

MUNANGA, Kabengele. Uma abordagem conceitual das noçóes de raça, racismo, identidade e etnia. Disponível em: <https:/www.ufmg.br/inclusaosocial/?p=59>. Acesso em: 19 ago. 2016. NEVES, Marcelo. Entre Têmis e Leviatã: uma relação difícil. 2. ed. São Paulo: Martins Fontes, 2008

PIOVESAN, Flávia. Proteção dos direitos humanos sob as perspectivas de raça, étnica, gênero e orientação sexual. Revista da Faculdade de Direito da PUC-SP, São Paulo: PUC, vol. 2, 2014. SOARES, Sergei Suarez Dillon Soares. O perfil da discriminação no mercado de trabalho homens negros, mulheres brancas e mulheres negras. Instituto de Pesquisas Econômicas Aplicadas (Ipea), 2000. Texto para Discussão n. 769. Disponível em: <http://www.ipea.gov. br/portal/images/stories/PDFs/TDs/td_0769.pdf>. Acesso em: 19 nov. 2015. 